\title{
The Relation between Suicide by Chemical Substances and the Level of Education
}

\author{
DAN PERJ U DUMBRAVA ${ }^{1}$, CARMEN CORINA RADU2*, DANIEL TABIAN ${ }^{3 *}$, STEFAN CRISTIAN VESA ${ }^{1}$, IULIU FULGA*, \\ OVIDIU CHIROBAN ${ }^{1}$ \\ IIuliu Hatieganu University of Medicine and Pharmacy, 8 Victor Babes Str., 400012, Cluj-Napoca, Romania \\ 'University of Oradea, Faculty of Medicine and Pharmacy, 101 Decembrie Sq., 410068, Oradea, Romania, \\ ${ }^{3}$ Grigore T. Popa University of Medicine and Pharmacy, 16 Universitatii Str., 700115, lasi, Romania \\ ${ }^{4}$ Dunarea de Jos University, Faculty of Medicine, 47 Domneasca Str., 800008, Galati, Romania
}

The study aimed to determine the influence of the levels of education among people that committed suicide by the use of chemical substances. Data were collected from 2 groups of subjects investigated at the Institute of Legal Medicine in Cluj-Napoca, between January 2012 and December 2016. The first group consisted of 20 deceased persons that committed suicide by chemical substances and the second group consisted of 13 persons that attempted suicide by chemical substances. We investigated the following data: gender, age and type of toxic substance, level of education, field of study, existence of mental illness or other attempts. Age was statistically significantly higher in successful suicides versus suicides attempts. The rest of the variables did not differ statistically significantly between groups, although a higher percentage of subjects with psychiatric illness were observed in the completed suicides group. Also, a higher percentage of subjects who attempted to commit suicide with combination of alcohol and other chemical substances were observed, without achieving statistical significance. We also analyzed the differences within the group with completed suicide subjects from the point of view of their studies. Although we did not get a statistical significance because of the low number of subjects, there were a few associations that slightly exceeded the statistical significance threshold. Thus, those withouthigher education have used alcohol more frequently in combination with medication, and those with higher education have preferred medication alone. The obtained results may have implications for the targeted prevention of suicides by chemical substances.

Keywords: suicide, chemical substances, level of education, forensic medicine

Suicide is an important medico-legal issue, contributing to the violent causes of death autopsied yearly. Suiciders come from all walks of life, and the methods of suicide are influenced by their social and cultural background. Among the most common methods of suicide in Romania, there are hanging, jumping from height and self-intoxications $[1,2]$. On the other hand, in the United States of America, due to the firearms permissive policy, death by shooting is the most common suicide method [3]. Likewise, in highly urbanized places with many skyscrapers, such as Singapore or Hong-Kong, jumping from height is frequently encountered $[4,5]$. In geographic regions where agriculture plays a major economic role, poisoning by solid/liquid substances, mainly pesticides, is the most common way to suicide $[6,8]$.

Chemical substances have been used in suicide purposes for centuries. Due to their rapid action, accessibility, and lack of mutilation of the body, the toxic agents are a common way of taking one's own life. A selfpoisoning suicide can by defined as the self-exposure of an individual (by ingestion or another route of administration) to an amount of substance associated with the significant potential to cause death [9].

The existing literature has examined the link between socio-economic conditions and their influence upon different disease. Considering suicide as a major global health problem, any study of its characteristics might prove useful to the public health policies implied in the prevention of this pathological phenomenon. Hence, there are many extensive literature studies, whether and to what extent the risk of suicide is linked to unemployment and economic recessions $[10,11]$. However, in our study we tried a more specific approach towards the phenomenon of suicide, by studying only the suicides by chemical substances. The study aimed to determine the relation between the levels of education among people that committed or attempted suicide by the use of chemical substances.

\section{Experimental part \\ Methods}

The study was retrospective, observational, analytical, transversal, and case-control.

We have included in the study two groups of subjects who have been expertized at the Institute of Forensic Medicine Cluj-Napoca between January 2012 and December 2016.

The first group was that of completed suicides, all the subjects having been autopsied. In these cases, a complete forensic autopsy was performed including complementary examinations: histopathological and toxicological analysis. The autopsies were performed at more than $6 \mathrm{~h}$ after the death and at no more than $24 \mathrm{~h}$ after the death. The biological samples collected for toxicological analysis were as follows: blood from the skull, urine from the bladder and tissue from liver and kidney. This group consisted of 20 patients with an average age of $45(32.5,64.7)$ years, including $12(60 \%)$ women and $8(40 \%)$ men, who died post self-intoxication. There were included subjects who met the inclusion criteria: the medical cause of death acute intoxication; the type of death from a medical-legal point of view - violent death; the legal type of death - suicide. 
The medical cause of death by acute poisoning was established by considering the chemical agent's action as a determining factor in the thanatogenerator chain. The type of death from a medical-legal point of view has been established by direct reporting to the medical cause of death. The juridical type of death has been established by taking into account the data found in the Ordinances for the Execution of Necropsy issued by the Criminal Investigative Institutions, mainly by the mentioning of the existence of suicides notes.

Subjects with a cause of death other than acute intoxication were not included even if they were found positive for chemical substances; we have also excluded the subjects with non-violent deaths, where the chemical factor did not play a determining role and also the accidental deaths and homicides.

The following data were recorded: gender, age, type of toxic substance, level of education, field of study, mental illness, other attempts, cerebral atherosclerosis and cirrhosis.

The second group was that of subjects with suicide attempt, being expertised by a forensic-psychiatry commission. This group consisted of 13 patients with a mean age of $20(16 ; 33)$ years, of which $10(76.9 \%)$ women and $3(23.1 \%)$ men, alive. There were included subjects who met the inclusion criteria: attempted suicide by using chemical substances.

We have not included subjects with accidental or criminal poisoning or those with suicide attempts with nonchemical agents.

The following data were recorded: gender, age, type of toxic substance, level of education, field of study, mental illness or other attempts.
The statistical analysis was performed with the MedCalc Statistical Software version 19.0.4 (MedCalc Software bvba, Ostend, Belgium, https://www.medcalc.org, 2019). Quantitative data were expressed by median and percentile 25 and 75 (non-normal distribution). Qualitative data were expressed by frequency and percentage. Group comparisons were made with the chi-square or the MannWhitney test depending on the situation. A $p<0.05$ value was considered statistically significant.

\section{Results and discussions}

The differences between the completed and attempted suicides, can be seen in Table 1. The age was statistically significantly higher in completed suicides in comparison with attempted suicides. Regarding the rest of the variables, we have found no statistically significantly difference between the two groups, although a higher percentage of subjects with psychiatric illness was observed in the completed suicides group. Also, a higher percentage of subjects who attempted to commit suicide with combination of alcohol and other chemical substances can be observed, without achieving statistical significance.

We analyzed the differences within the group with completed suicides subjects from the point of view of their studies. Although we did not obtained a statistical significance because of the low number of subjects, we did observe few associations that slightly exceeded the statistical significance threshold. Thus, those without higher education have used alcohol more frequently in combination with medication, and those with higher education have preferred medication alone. Cerebral atherosclerosis was more common in those with primary and secondary education.

\begin{tabular}{|c|c|c|c|c|}
\hline \multicolumn{2}{|l|}{ Variable } & Attempted suicides (13) & Completed suicides (20) & $\mathbf{p}$ \\
\hline \multicolumn{2}{|l|}{ Age } & $20(16 ; 33)$ & $45(32.5 ; 64.7)$ & 0.001 \\
\hline \multirow[t]{2}{*}{ Gender } & $F$ & $10(76.9 \%)$ & $12(60 \%)$ & \multirow[t]{2}{*}{0.4} \\
\hline & $\mathrm{M}$ & $3(23.1 \%)$ & $8(40 \%)$ & \\
\hline \multirow[t]{3}{*}{ Level of education } & Primary & $4(30.8 \%)$ & $3(15 \%)$ & \multirow{3}{*}{0.4} \\
\hline & Secondary & $4(30.8 \%)$ & $5(25 \%)$ & \\
\hline & Superior & $5(38.5 \%)$ & $12(60 \%)$ & \\
\hline \multicolumn{2}{|l|}{ Psychiatric diseases } & $2(15.4 \%)$ & $8(40 \%)$ & 0.2 \\
\hline \multicolumn{2}{|l|}{ Other attempts } & $2(15.4 \%)$ & $5(25 \%)$ & 0.6 \\
\hline \multirow[t]{3}{*}{ Benzodiazepines (BZD) } & No & $8(61.5 \%)$ & $10(50 \%)$ & \multirow{3}{*}{0.4} \\
\hline & BZD + alcohol & $4(30.8 \%)$ & $5(25 \%)$ & \\
\hline & BZD & $1(7.7 \%)$ & $5(25 \%)$ & \\
\hline \multicolumn{2}{|c|}{ BZD alone } & $1(7.7 \%)$ & $5(25 \%)$ & 0.3 \\
\hline \multicolumn{2}{|c|}{ Alcohol + other chemical substances } & $6(46.2 \%)$ & $5(25 \%)$ & 0.2 \\
\hline
\end{tabular}

Table 1

COMPARISONS BETWEENTHE COMPLETED SUICIDES GROUP AND THE ATTEMPTEDSUICIDES GROUP

\section{Table 2}

COMPARISONSBETWEEN THE SUBJ ECTSWITH SUPERIOR EDUCATION ANDTHOSE WITH PRIMARY AND SECONDARY EDUCATION WITHIN THE GROUP OF COMPLETED SUICIDES

\begin{tabular}{|c|c|c|c|c|c|}
\hline \multicolumn{2}{|c|}{ Variable } & Primary and secondary & education (8) & Superior education (12) & $\mathbf{P}$ \\
\hline \multicolumn{2}{|l|}{ Age } & $55(22 ; 33$ & & $45(32.5 ; 64.7)$ & 0.5 \\
\hline \multirow[t]{2}{*}{ Gender } & $F$ & $5(62.5 \%)$ & & $7(58.3 \%)$ & \multirow[t]{2}{*}{1} \\
\hline & $\mathrm{M}$ & $3(37.5 \%)$ & & $5(41.7 \%)$ & \\
\hline \multirow[t]{2}{*}{$\mathrm{BZD}$} & $\begin{array}{l}\text { Nu } \\
\text { BZD +alcohol }\end{array}$ & $\begin{array}{l}3(37.5 \%) \\
4(50 \%)\end{array}$ & & $\begin{array}{l}7(58.3 \%) \\
1(83 \%)\end{array}$ & \multirow[t]{2}{*}{0.1} \\
\hline & BZD & $1(12.5 \%)$ & & $1(33.3 \%)$ & \\
\hline \multicolumn{2}{|c|}{$\begin{array}{l}\text { BZD alone } \\
\text { Alcohol + other chemical substances }\end{array}$} & $\begin{array}{c}1(12.5 \%) \\
4(50 \%)\end{array}$ & & $\begin{array}{l}4(33.3 \%) \\
1(83 \%)\end{array}$ & $\begin{array}{l}0.6 \\
0.1\end{array}$ \\
\hline \multicolumn{2}{|c|}{ Peychiatric dieeazae } & $1(50 \%)$ & & $1(33.3 \%)$ & 0.6 \\
\hline \multirow{2}{*}{\multicolumn{2}{|c|}{$\begin{array}{l}\text { Other attempts } \\
\text { Cerebral atherosclerosis }\end{array}$}} & $2(25 \%)$ & & $3(25 \%)$ & 1 \\
\hline & & $4(50 \%)$ & & $2(16.7 \%)$ & 0.1 \\
\hline \multicolumn{2}{|c|}{ Hepatic cirrhosis } & $2(25 \%)$ & & $1(83 \%)$ & 0.5 \\
\hline
\end{tabular}




\section{Conclusions}

The specialty literature is poor in studies regarding the association between suicide by chemical substances and the level of education of the victims. However, we have come across studies concerning the association between suicide and the economic level of victims [12], respectively studies of the epidemiological parameters of suicidal victims by chemical substances [9]. Thus, the presentstudy represents a new perspective on the understanding of the suicidal phenomenon through the use of chemical agents.

Regarding our result according to which the age was statistically significantly higher in completed suicides in comparison with attempted suicides, this is consistent to the existing literature data [13].

A higher percentage of subjects with psychiatric illness was observed in the completed suicides group. This fact is also explainable by the known relation between the existence of mental illness and suicide. Also, a higher percentage of subjects who attempted to commit suicide with combination of alcohol and other chemical substances can be observed, without achieving statistical significance. We have a possible explanation for this, given by the impulsivity increases associated with alcohol consumption.

With reference to our result regarding the use of the combination of alcohol and medication (mainly benzodiazepines) as a suicidal method, in patients without higher education, in comparison with those with higher education that had preferred medication alone, we consider that the following observations are required. First of all, it is well-known that alcohol is a widely available and cheap toxic and is very easy to obtain. Hence, the subjects without higher education might be more inclined to abuse alcohol alone, than medication, and use it as a main chemical substance in suicides. Another explanation could be related to the direct connection between the level of education and the economic status, meaning that subjects with superior education are more likely to earn more money than subjects with primary and secondary education. Therefore, the abuse substances in this group might be more diversified and expensive than alcohol, and could also be chosen as main toxics in suicide attempts. The medication used in our subjects, mainly benzodiazepines is relatively hard to get in Romania. We might assume that, when BZD were found to be positive in our subjects, this was due to the following facts: either they were psychiatric patients under medical treatment or they were doctors and had easily access to these substances, or both. The fact that the subjects with superior education were more likely to commit suicide only by medication, might have the following explanations: we have included many doctors in our study and also medication is a substance used for abusing, in intellectuals.

The symptoms and the effects of the three phases of acute alcohol intoxication are well known in the general population [14]. If the signs and symptoms of the first phase of alcohol intoxication $(<1.5 \mathrm{~g} \%$ ) can be considered relatively pleasant and harmless (logorrhea, disinhibition, relaxation, ideation, etc.), the symptoms of the second phase, also called the forensic phase (in which antisocial deeds happen, and which occur between $1.5 \mathrm{~g}$ $\%$ and $3 \mathrm{~g} \%$ ) are unpleasant (loss of balance, falls, dizziness, vomiting, aggression, etc.) [13]. In the third phase of acute alcoholic intoxication, coma and death occur [14]. Usually, from the medical-legal point of view we consider that a person had died as a result of alcohol consumption, if we notice a postmortem value of alcohol in excess of 3 $9 \%$ [16]. In interpreting these values, we have to take into account the possibility of postmortem alcohol production which might appear in putrefaction. However, all the autopsies taken into account for this study didn't have any rotting state subjects.

Death in acute alcohol intoxication usually occurs due to central nervous system inhibition. The main effect of alcohol upon the central nervous system is inhibition and not excitation. The same effect occurs after benzodiazepines use. Therefore, when combining alcohol and benzodiazepines the effect sums up, and death occurs easier, making this combination very effective in suicides [17]. But this combination of the two toxics might also lead to an accidental death. It not very uncommon for a subject to abuse both alcohol and BZD. In accordance, without any suicidal intention, this combination might prove fatal, because the subjects ignore the summing and synergic effect of the two substances. This the reason for which, in our study we included only the subjects that had previously written suicides notes.

Cerebral atherosclerosis was more common in those with primary and secondary education. This result might prove the fact that intellectual activities inhibit cerebral atherosclerosis, in opposition with non-intellectual activities, thus being an encouraging result for the authors of this study and also to its readers. To sum up, the results obtained in our study, might prove to be useful for the clinicians involved in preventing suicide in general and specifically suicide in subjects who are more inclined to abuse chemical substances, by carefully assessing their suicidal risk, taking into account the level of their education.

\section{References}

1.BULGARU-ILIESCU D., BOTEZAT D., OPREA L., The chronic care model and personal responsibility for health, Revista Romana de Bioetica, 2012, vol. 10(4): 78-84

2.*** Raport asupra activitatii retelei de medicina legala in anul 2018. Avilable at: https://www.legmed.ro/doc/dds2018.pdf. Accessed 18J une 2019.

3.AJDACIC-GROSS, V., WEISS, M.G., RING, M., HEPP, U., BOPP, M., GUTZWILLER, F., RÖSSLER, W., 2008. Methods of suicide: international suicide patterns derived from the WHO mortality database. Bull. World Health Organ 86, 726-732.

4.WONG, P.W., CAINE, E.D., LEE, C.K., BEAUTRAIS, A., YIP, P.S., 2014. Suicides by jumping from a height in Hong Kong: a review of coroner court files. Soc. Psychiatry Psychiatr. Epidemiol. 49, 211-219.

5.CHIA, B.H., CHIA, A., NG, W.Y., TAI, B.C., 2011. Suicide methods in Singapore (2000-2004): types and associations. Suicide Life Threat. Behav. 41, 574-583.

6.WU, K.C.C., CHEN, Y.Y., YIP, P.S., 2012. Suicide methods in Asia: implications in suicide prevention. Int. J. Environ. Res. Public Health 9, 1135-1158.

7.IOVTATIANA, COSTESCU MIHNEA, DIAC MADALINA, TABIAN DANIEL, DAVID SOFIA MIHAELA, KNIELING ANTON, DAMIAN SIMONA IRINA, Dangerous Chemical Agents: General and Odonto-Stomatological Aspects with Importance in Forensic Toxicology, Revista de Chimie, 2019, vol. 70(5): 1829-1834

8.SCRIPCARU VERONICA, IOV TATIANA, KNIELING ANTON, DAVID SOFIA MIHAELA, RADU CARMEN CORINA, Suicide and blood types, Romanian Journal of Legal Medicine, vol. 26(2): 206-208

9.GHARBAOUI, M., BEN KHELIL, M., HARZALLAH, H., BENZARTI, A., ZHIOUA, M., HAMDOUN, M., Pattern of suicide by self-poisoning in Northern Tunisia: An eleven-year study (2005-2015), J ournal of Forensic and Legal Medicine 61 (2019) 1-4.

10.BARR, B., TAYLOR-ROBINSON, D., SCOTT-SAMUEL, A., MCKEE, M., STUCKLER, D., 2012. Suicides associated with the 2008-10 economic recession in England: time trend analysis. BMJ 345, e5142. 11.COOPE, C., GUNNELL, D., HOLLINGWORTH, W., HAWTON, K., KAPUR, N., FEARN, V., WELLS, C., METCALFE, C., 2014. Suicide and the 2008 economic recession: who is most at risk? Trends in suicide 
rates in England and Wales 2001-2011. Soc. Sci. Med. 117, 76-85.

12.VANDOROSA, S., AVENDANOA, M., KAWACHIB, I., The association between economic uncertainty and suicide in the short run. Social Science and Medicine 220 (2019) 403-410.

13.CONWELL, Y., DUBERSTEIN, P. R., COX, C., HERRMANN, J. H., FORBES, N. T., \& CAINE, E. D. (1996). Relationship of age and Axis I diagnoses in victims of completed suicide: A psychological autopsy study. The American J ournal of Psychiatry, 153(8), 1001-1008.

14.J YANI, G., PRINJA, S., AMBEKAR, A., BAHUGUNA, P., KUMAR, R., Health impact and economic burden of alcohol consumption in India, International J ournal of Drug Policy Volume 69, J uly 2019, Pages 34-42.
15.PERJU-DUMBRAVA, D., Legal medicine. Lecture support, Editura Universitara Iuliu Hatieganu Cluj-Napoca, 2017.

16.PERJU DUMBRAVA, D., RADU, C.C., IOV, T., DAMIAN, S., SANDU, I., TIMOFTE, D., CHIROBAN, O., An Unusual Case of Accidental Carbon Monoxide and Ethanol Intoxication in Two Commorientes Deaths, Rev. Chim. (bucharest), 69, no. 7, p. 1889-1891.

17.BRADY, J., The association between alcohol misuse and suicidal behavior. Alcohol Alcohol. 41, 473-478.

Manuscript received: 26.11 .2018 